\title{
artículos
}

\section{Roma, archipiélago de la memoria. La ciudad del Duce entre mito, proyecto y realidad}

\author{
Belén Calderón Roca \\ Grupo de investigación HUM 130. Universidad de Málaga.
}

\section{RESUMEN}

Entre 1922 y 1945 el gobierno fascista trató de aproximar la ciudad de Roma a la sociedad italiana mediante el direccionamiento arquitectónico, la reinvención de su pasado histórico y la sacralización del mito de la Romanidad. Benito Mussolini, promotor absoluto de la resurrección de la grandeza imperial de la antigüedad romana, fue el artífice de una política de masas dirigida a consolidar la hegemonía del fascismo mediante una imagen urbana que ofrecía secuencias inconexas, falseadas y descontextualizadas de la realidad. En qué medida la historia de la urbe romana, capturada por la doctrina fascista y en concreto, por el pensamiento del Duce, es deudora del estrato mitológico quedará expuesto en estas páginas.

PALABRAS CLAVE: Benito Mussolini/ Urbanismo/ Arquitectura/ Historia/ Fascismo/ Tradición/ Mitología.

Rome, archipelago of the memory. The city of the Duce between myth, project and reality

ABSTRACT

Between 1922 and 1945 the fascist management try to approach Roma city to the Italian society by means of the architectonic way, make up the historical past and the sacralising of the Ancient Roman's myth. Benito Mussolini, absolute promoter of the resurrection of Ancient Roman's grandeur, was the author of one mass politic direct to consolidate the hegemony of the fascism by means of urban image that offered sequences unconnected, disort and out of reality context. In what extent the roman urban history, to catch for the fascist doctrine, and specifically, for the Duce's thinking is debtor of the mythologic stratum will be exhibit in this pages.

KEY WORDS: Benito Mussolini/ Town Planning/ Architecture/ History/ Fascism/ Tradition/ Mythology.

EL MITO.

\begin{abstract}
"Sacralizar la memoria es otro modo de hacerla estéril", TZVETAN TODOROV, Los abusos de la memoria (2008).

"El mito priva de cada historia al objeto de su discurso. $Y$ en tal caso la historia se evapora...". BARTHES R., Mitti d'oggi (1957) 1 .
\end{abstract}

El peso que adquiere la formación de mitos dentro de la cultura contemporánea, con respecto a las propiedades estructurales de la conciencia humana se revela con certeza. Gillo Dorfles plantea en su tesis la alternancia simultánea de mitos tradicionales y la aparición de nuevos procesos de mitificación inconscientes e irracio-

* CALDERÓN ROCA, Belén: "Roma, archipiélago de la memoria. La ciudad del Duce entre mito, proyecto y realidad", en Boletín de Arte, n 30-31, Departamento de Historia del Arte, Universidad de Málaga, 2009-2010, págs. 367-384. Fecha de recepción: Septiembre de 2009.

1 Todas las traducciones en italiano han sido realizadas de forma libre por la autora. 
nales, de los que surgen como consecuencia, otra serie de mitos y símbolos ${ }^{2}$. Los mitos emergen y se van consolidando a través del tiempo, como forma de comunicación tácita o explícita, y trascienden a las actividades intelectuales, a la producción artística, al lenguaje y a la vida espiritual de las sociedades, que los van incorporando incluso a realidades no condicionadas como el ser, la verdad o el valor ${ }^{3}$.

Admitimos el carácter narrativo del mito y su estructura semiológica, aceptándolo como un sistema de comunicación o lenguaje que transmite un mensaje concreto ${ }^{4}$. En su definición, el mito se construye asumiendo la representación mental o simbólica de una historia sagrada o bien, sacralizada, que relata hechos o acontecimientos que han tenido lugar en un tiempo preciso y significativo, asumiéndose universalmente como tal ${ }^{5}$. El mito, como lenguaje, hace referencia a una realidad obtenida a partir de una selección, independientemente de su objetividad o subjetividad, que debe proporcionar modelos de conducta a un individuo o grupo social, aportando sentido a su existencia 6 .

La identificación de las argumentaciones personales con los mitos se efectúa de acuerdo a una misión específica, que Leszek Kolakowski califica como una triple necesidad7.

En primer lugar, se trata de una necesidad de ser comprendido; de llenar de sentido la propia experiencia, legitimándola y relacionándola con una realidad no condicionada.

En segundo lugar, la necesidad de detener el espacio temporal y enmascarar la realidad con la continuidad de la forma mítica del tiempo. Exigencia de creer en la permanencia del pasado acumulado y detenido. Todo mito implica un sistema de valores propio en cuanto supone un recorte de la realidad ${ }^{8}$. Para lograr que un mito sea eficaz, a nivel temporal, estos valores deben tener un carácter irreversible, cíclico y sempiterno, y simbolizar la posibilidad de un renacimiento continuo 9 .

En tercer lugar, la necesidad de afianzar los valores constituye un tipo de herencia objetivada por la sociedad, con una duración determinada tendente a la desaparición. La estabilidad de los valores queda garantizada por la conciencia mítica, y el mitificador los dogmatiza, inclusive hasta el punto de cristalizar en doctrina. No obstante, la irracionalidad del mito sobrevendrá cuando en un grupo social, en vez de satisfacer las necesidades de los individuos, se tienda a crear otras nuevas falsificadas, irreales e ilógicas que se impongan a las otras con prioridad indiscutible.

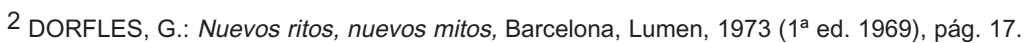

3 KOLAKOWSKI, L.: La presencia del mito, Madrid, Cátedra, 1990 (1ª ed. 1972), págs. 9-11.

4 BARTHES, R.: Mythologies, Paris, Le SEuil, 1957, pág. 215.

5 PARAMIO, L.: Mito e ideología, Madrid, 1971, págs. 7-8 y 11.

6 ELIADE, M.: Mito y realidad, Madrid, Guadarrama, 1968, pág. 14.

7 KOLAKOWSKI, L.: op. cit., págs. 14-16.

8 BARTHES, R.: op. cit., pág. 36

9 ECO, U.: Apocalípticos e integrados, Barcelona, Lumen, 1978, pág. 265. 
La aparición de formas de consciencia humana que justifiquen la perpetuación de este sistema de estructura mitológica impuesta es calificada de ideología ${ }^{10}$, como en el caso del fascismo. Al igual que sucede con el mito, la ideología fascista proporciona un falso modelo de realidad que enmascara el verdadero objeto de conocimiento de un hecho o acontecimiento. Efectivamente, el mito se convierte en portador de una verdad particular, objetiva o subjetiva, para la que no existe modo alguno de confirmación empírica, pues no existe ningún acceso directo a ella que no haya sido contaminado por influencias filosóficas y literarias ${ }^{11}$.

En cualquier caso, para la formación de mitos se suele recurrir a testimonios de diversa índole que sirvan para fortalecer, invalidar o completar la información de la que disponemos, igual que sucede con la información que tenemos acerca de un acontecimiento, cuando no conocemos con certeza la totalidad de las circunstancias que lo rodearon. Es posible que nos suceda al regresar a una ciudad que hemos visitado anteriormente, que aquello que percibimos al presente nos ayude a recomponer la imagen mental que teníamos, o bien, a recordar fragmentos de ella olvidados. Evidentemente, la percepción actual se ubica en el contexto de los recuerdos pretéritos, pero al mismo tiempo, ambas percepciones -pasada y presente- interactúan confrontándose simultáneamente, encontrando concordancias y divergencias en la búsqueda del reconocimiento de esa imagen inicialmente formada. Pero hemos de ir aún más lejos, nuestra confianza en la exactitud de los hechos puede basarse no sólo en nuestros recuerdos o impresiones, sino también en las aportaciones ofrecidas por los demás, generando, modificando o rectificando nuestra imagen ${ }^{12}$. Ello nos remite ineludiblemente a la filosofía del conocimiento de Maurice Halbwachs ${ }^{13}$, para quien la memoria nace indefectiblemente de una construcción social, y justamente, la sociedad actúa como agente contextualizador y espejo de dicha memoria. Pues bien, memoria personal y memoria colectiva son manifestaciones de un mismo fenómeno social, de un idéntico lenguaje colectivo y de un sistema de convenciones, reglas y determinantes culturales propios. Naturalmente, la memoria colectiva suscita el sentimiento de continuidad histórica y la identificación del individuo con la comunidad, de acuerdo a intereses y creencias semejantes: "La memoria colectiva es un capital social intangible"14. Pero supongamos que no exista ningún testigo material y sensible de un hecho. Un individuo puede reunir a través de sus propios recuerdos descripciones de hechos o acontecimientos con gran exactitud, aún en los casos en los que las realidades de los mismos no sean discutibles, como por ejemplo, los mitos. Es decir, en muchas ocasiones nos encontramos ante datos abstractos que resulta imposible asociar a ningún recuerdo real, y a pesar de ello, podemos ubicar-

\footnotetext{
10 PARAMIO, L.: op. cit., págs. 96-97.

11 GADAMER, H. G.: Mito y razón, Barcelona, Paidós, 1997 (1ª ed. 1993 Siebeck, P., Turinga), pág. 42.

12 HALBWACHS, M.: La memoria colectiva, Zaragoza, Prensas Universitarias de Zaragoza, págs. 25-26.

13 Ibídem.

14 COLMEIRO, J. F.: Memoria histórica e identidad cultural, Barcelona, Anthropos, 2005, pág. 15.
} 


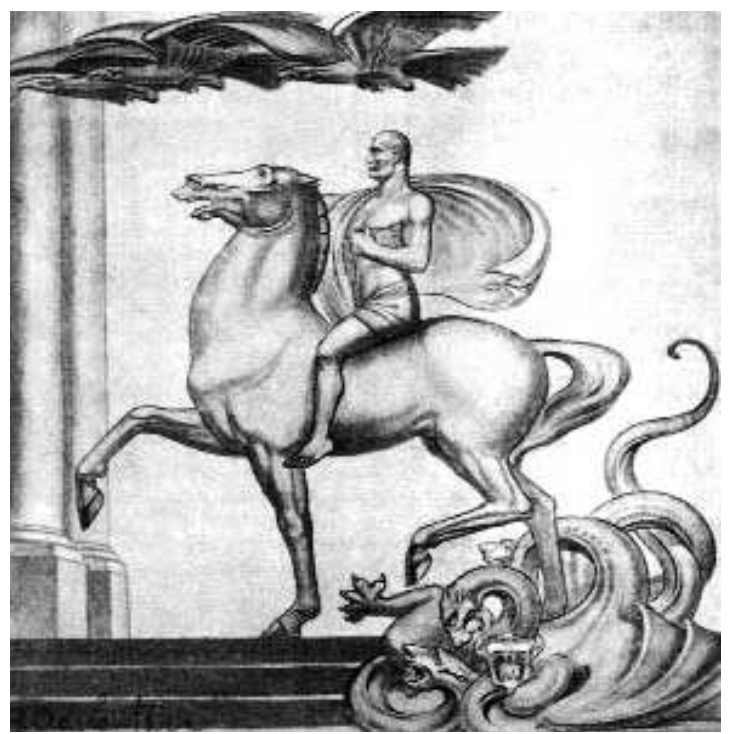

1. "Mussolini a cavallo", s.f., GugLIELMo CiarLANTINI, Palazzo Comunale di Corridonia, Italia.

los en el tiempo y el espacio. Basta con que otro individuo los evoque ante nosotros y nos facilite datos para la recomposición del hecho, pieza a pieza, a través de la construcción de la imagen mental que hacemos del mismo. Al alimentar reiteradamente la construcción mental de una imagen, asimilamos ésta como algo que realmente ha sucedido y dicha imagen consigue transformarse en recuerdo ${ }^{15}$. Desde el momento en que los individuos que son testigos de un hecho, o bien, son creadores de un determinado recuerdo o ideología, y aquéllos que no lo son, compartan pensamientos afines y sean capaces de identificarse como grupo, podrán llegar a confundir recuerdos y experiencias mutuas, desarrollando una memoria colectiva que se limitará a la intensidad de cohesión y duración de dicho grupo ${ }^{16}$. La memoria colectiva se distingue de la historia por ser una corriente de pensamiento con continuidad, es decir, posee la capacidad de rememorar aquellos fragmentos del pasado que son significativos para la conciencia del grupo que la mantiene; mientras que el grupo exista, existirá el interés por un determinado período histórico ${ }^{17}$.

Llegados a este punto, subyacen analogías entre el funcionamiento de la memoria colectiva defendido por Halbwachs, y el concepto de ideología de Althusser, como sistema de ideas o representaciones de la realidad que sirven para legitimar a

\footnotetext{
15 HALBWACHS, M.: op. cit., pág. 28.

16 Ibídem., pág. 29-30.

17 Tal y como define Maurice Halbwachs, a diferencia de la memoria histórica, la historia supone la sucesión de períodos históricos que se renuevan junto con tradiciones, grupos sociales, intereses o perspectivas de estudio. Ibídem., pág. 81.
} 
artículos Roma, archipiélago de la memoria. La ciudad del Duce..

un grupo social ${ }^{18}$. Si tenemos en cuenta que cada grupo social se esfuerza por mantener un nivel de persuasión suficiente entre sus miembros, con la intención de prolongar la adhesión de éstos al grupo mediante recuerdos, pensamientos o ideologías que le son propios, existen ocasiones, en las que la memoria colectiva envuelve a las memorias individuales según las leyes del grupo y las exceptúa colectivamente. En este caso, el bagaje de recuerdos históricos pierde toda su independencia y éstos únicamente podrán ser proporcionados por el entorno 19. Pues bien, si trasladamos este argumento al núcleo de nuestro trabajo, el fascismo actúa incidiendo en la formación inicial de los recuerdos de una ciudad inexistente y una historia irreal, sostenidos por la alimentación de un mito, que no es sino un hecho cuya realidad no es discutible. De este modo algunas ideas o símbolos se presentan bajo una imagen popular y accesible a la imaginación, al reconocimiento y al sentimiento de identificación. Llegados a este punto, la doctrina fascista estimula la construcción de una imagen mental pretérita convertida en recuerdo: la solemnidad de antigüedad clásica y las victorias de la Roma imperial confrontada con el presente, evocando la glorificación de los emperadores a través de la construcción del mito, necesario para aunar pasado y presente en la figura del Duce.

\section{EL PROYECTO.}

La Marcia su Roma en 1922, supondrá la llegada de Benito Mussolini al poder y el inicio del desarrollo de una política dictatorial fuertemente centralizada que transformará la realidad político-social italiana. La dictadura fascista se reflejará inmediatamente en el campo de la cultura, así como en las fuerzas intelectuales y artísticas del país, pues el gobierno llegó a imprimir en las letras aspectos derivados del carácter nacional, creando una literatura propiamente italiana. Aunque producida circunstancialmente, junto con la edición de revistas oficiales, ésta abarcaba un conjunto de obras más o menos afortunadas sobre cultura fascista que pretendían elogiar a Mussolini y su labor, así como proveer al Partido de una respetabilidad doctrinal, pero que en cualquier caso, constituyeron un magnífico documento para ilustrar la historia del fascismo 20 . Conviene recordar que la promoción de una cultura propiamente fascista, surgió de la necesidad de dotar a la literatura, al arte y al pensamiento italianos de universalidad e internacionalidad, facilitando la accesibilidad de las masas ${ }^{21 .}$

18 COLMEIRO, J. F.: Memoria histórica e identidad cultural, Barcelona, Anthropos, 2005, pág. 16-17; Vid. ALTHUSSER, L.: Ideología y aparatos ideológicos de Estado: Freud y Lacan, Buenos Aires, Nueva Visión, 2003

19 HALBWACHS, M.: op. cit., pág. 54.

20 Cabe destacar la aparición de la revista Architettura (antigua Architettura e Arti Decorative) en 1927, primera revista italiana dedicada a la ciudad antigua y a las nuevas tendencias arquitectónicas, que se convertirá en el órgano difusor oficial del Sindacato Fascista degli Architetti.

21 PEÑA SÁNCHEZ, V.: Intelectuales y fascismo. La cultura italiana del 'ventennio fascista' y su repercusión en España, Granada, Universidad, 1995, págs. 124-125. 


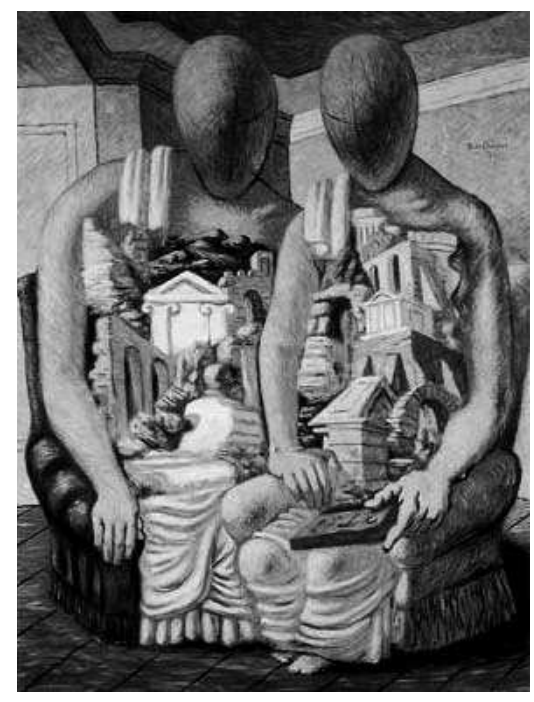

2. "Archeologi", GIORGIO DE CHIRICO, 1937

Aunque la antinomia fascismo-cultura provocó un desdoblamiento en el comportamiento de algunos intelectuales 22 ; por una parte, los que se opusieron a ser manipulados por el gobierno, y por otra, los que se declararon partidarios del partido fascista y vieron en el nuevo régimen un clima favorable y oportunidades para la creación. El debate cultural tan sólo podía desarrollarse por parte de éstos últimos, que debían someterse al férreo control del Estado. Se impuso una implacable censura sobre los medios de masas (radio y cine) y sobre la prensa, así como sobre la burguesía, considerada el grupo social que ejercía mayor presión cultural y económica. Se produjo un retorno a la exaltación de la tradición y sus valores, fomentando el culto a la romanidad mediante el uso de una retórica triunfalista de la patria. En los años veinte, el mito de la antigüedad clásica comienza a convertirse, a través de la revalorización de los vestigios arqueológicos, en fragmentos tangibles de la majestuosidad y excepcionalidad pretéritas. No obstante, tal y como apunta $\mathrm{M}^{\mathrm{a}}$ Teresa Méndez Baiges ${ }^{23}$, también ésta se ve distorsionada y modernizada en cierto modo por los arqueólogos, y se presta a ser satirizada. El pintor Giorgio de Chirico caricaturiza la arqueología a través del tratamiento que realiza en su pintura de las ruinas clásicas, exhibidas como universos portátiles y consumibles del pasado, accesibles a través de los medios que proporciona la modernidad.

Junto con el monopolio de los medios de comunicación, los viajes de Benito Mussolini por toda Italia constituyen otro soporte a la eficaz maquinaria de propagan-

22 Esta reacción fue denominada por Norberto Bobbio: “Nicodemismo”. Ibídem., pág. 102.

23 MENDEZ BAIGES, M. T.: Modernidad y tradición en la obra de Giorgio de Chirico, Madrid, UNAM, 2001, pág. 37. 


3. "Duce architetto".
Mussolini da el primer golpe
de piqueta para la construc-
ción del Foro Mussolini.
Roma, Istituto Luce. Archivio
Fotografico. 28-10-1937.

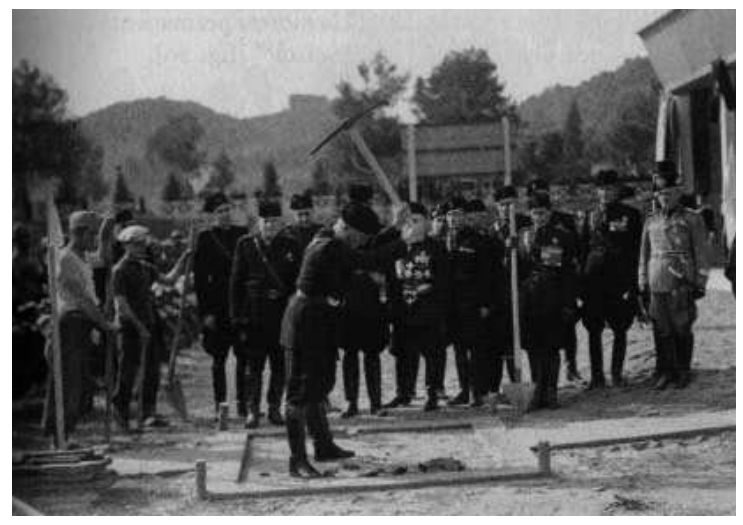

da del fascismo. Éstos se convierten casi en un ritual que coincide con fechas significativas del calendario fascista, y en Roma, Venecia, Florencia, Milán, Nápoles o Turín se inauguran frecuentemente escuelas, casas del fascismo, colonias paramilitares... para demostrar la voluntad de integración social del régimen ${ }^{24}$. Todas las obras emprendidas por Mussolini en su itinerario encerraban un significado político que las identifican con la figura del Duce, quedando envueltas por un aura sagrada que las convertía en símbolos locales del fascismo25. Movido por la necesidad de ser aprehendido, el Duce se encamina a hacia una poderosísima estrategia populista, sin duda, para lograr la adhesión de las masas al régimen como base de una política de base fideística y emotiva26: "La apparizione del regime in un horizonte storico mitizzato, che trasforma la percezione del tempo cuotidiano in qualcosa di straordinario, di unico"27. De este modo, a los ojos del pueblo italiano Mussolini se inviste con el título de constructor de la nación, artífice de la nueva Italia que se sirve de la arquitectura para avivar el mito de sí mismo28.

La política de Mussolini se dirige fundamentalmente, hacia la creación de la Terza Roma, a través de la potente metáfora que suponía la resurrección del renacimiento imperial de Italia al unísono de fascismo y arquitectura. A tal efecto, Roma constituye la ciudad sine qua non para llevar a cabo la misión de recuperar la grandeza y esplendor de antaño, despertando sentimientos de pertenencia a la comunidad en el pueblo italiano y alimentando el orgullo nacional; de esta forma sería posi-

\footnotetext{
2423 de marzo día de la fundación del fascismo, 9 de mayo fundación del Imperio, 28 de octubre Marcia su Roma, etc. NICOLOSO, P.: Mussolini architetto. Propaganda e paesaggio urbano nell'Italia fascista, Torino, Einaudi, 2008, pág. 6. 

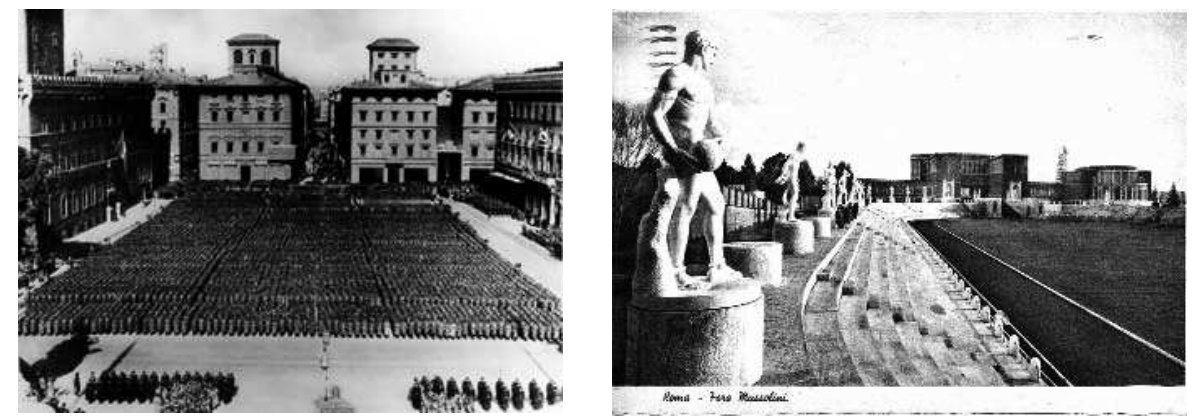

4. "La conquista de las masas". Desfile homenaje a Hitler en Piazza Venezia, Roma, Archivio Storico Capitolino (ASC), 1938.

5. Stadio dei marmi, en el Foro Mussolini (actualmente denominado Foro Italico). Tarjeta postal, s.a., $1939 \mathrm{ca}$.

ble superar incluso a las épocas romana antigua o renacentista: "Dopo la Roma di Augusto, dopo la Roma di Sisto V [si edificherà] la Roma di Mussolini"29. Resultaba necesario por tanto, llevar a cabo titánicas obras urbanísticas e inventar un estilo arquitectónico imponente duradero, que fuese pura manifestación artística espontánea de la cultura arquitectónica italiana, y que sin renunciar a la modernidad, contribuyese a relatar la memoria de la nación, sintetizando además, la tradición clásica y el esplendor de la Roma imperial:

"Durare! Durare giorno per giorno, mese per mese, anno per anno!30 Durare vuol dire affermare sempre di piú il regime, molteplicare le 'realizzazioni', fascistizzare al massimo gli italiani” 31 .

De este modo, la arquitectura es elegida como el mecanismo para el sostén de la disciplina fascista, participando del proceso totalizador de la sociedad y modificando el carácter, los hábitos y la mentalidad de los individuos ${ }^{32}$. La obra del Duce debe quedar plasmada en los monumentos como símbolo de la herencia espiritual del período fascista y para ello es necesario renovar la impronta en las ciudades. Con lo cual, los monumentos deben concebirse como la personificación de su figura, para que las masas puedan aclamarle no sólo en el presente, sino a través de la renovación sempiterna. Y las generaciones futuras podrán continuar glorificando los hitos monumenta-

29 “Il piano regolatore dell’Urbe nei rilievi della stampa romana”, en Popolo d'Italia, n 29, gennaio, 1931. 30 SUSMEL, D. (a cura di): Benito Mussolini: Opera Omnia, Firenze 1951-1981, vol. XXII, pág. 242.

31 DE FELICE, R. "La organizzazione dello Stato fascista 1925-1929", en Mussolini il fascista, vol. II, Torino, Einaudi, 1968, pág. 362.

32 NICOLOSO, P.: op. cit., págs. XV-XVI. 
les como ya se hizo en otros períodos históricos 33 : "Italia debe asumir su destino de desafiar al tiempo y formar la nueva base de la memoria histórica de los italianos"34.

Los primeros movimientos de vanguardia del siglo $X X$-entre ellos el Futurismo- sometieron la realidad artística decimonónica a un proceso de recomposición; una reconstrucción del tiempo y del espacio que se confió al arte, considerado el único instrumento capaz de conseguirlo, y el futurismo contribuyó sin lugar a dudas, a fundar y difundir la doctrina fascista: "Noi vogliamo glorificare la guerra -sola igiene del mondo- il militarismo, il patriotismo, il gesto distruttore dei libertarii..."35. Mussolini comparte el pensamiento de hacer de la guerra una gran empresa educativa, un instrumento litúrgico necesario para modelar el carácter de los italianos, exaltar la fuerza colectiva del país y transmitir sensación de unidad de la nación. Y nos llama la atención, que el mayor número de intervenciones en el campo urbanístico coincidan con el segundo conflicto bélico mundial ${ }^{36}$. Puede decirse que los futuristas reinterpretaron las raíces espirituales de la nación acomodándolas a los postulados fascistas, exponiendo como pretexto la forzosa adaptación de la sociedad a las exigencias de la vida moderna. Sin embargo, la reclamación de conservar los hitos monumentales como panegírico de la antigüedad imperial, situó a los futuristas en un segundo plano, fracasando éstos en el empeño de convertirse en el arte del Estado fascista. La presencia del fascismo en el mundo artístico y cultural se refrendaba por la existencia de una dialéctica entre modernidad y tradición. Aunque el Futurismo entraba en contradicción con dicha ideología, pues no servía para refrendar el carácter innovador que el fascismo debía asumir respecto de la historia y del pasado: "(...) eterna ed inutile ammirazione del passato, da ciu uscite fatalmente esausti, diminuti e calpesti?"37, parece que la Roma mussoliniana era capaz de asimilar tales postulados, que perseguían acabar con la imagen arcaizante de las ruinas y las arquitecturas decrépitas, incorporándolos a la visión triunfal de la antigüedad clásica. Mussolini se sirve indistintamente de estilos arquitectónicos diversos para desenvolver sus acciones de propaganda política y aunque en un principio no estaba de acuerdo con ese modernismo racionalista, a mitad de los años 30 admite la moderación y la posibilidad de combinar formas arquitectónicas novedosas y consonantes con los presupuestos ideológicos del fascismo: "Puó rinascere una grande arte che può essere tradizionalista e al tempo stesso moderna (...) bisogna creare I'arte nuova dei nostri tempi, l'arte fascista" 38.

Probablemente el Duce entendiese que la forma artística es deudora de un

\footnotetext{
33 SUSMEL, D. (a cura di): Benito Mussolini...op. cit., vol. XX, pág. 234.

34 Traducción libre de la autora. NICOLOSO, P.: op. cit., pág. XIX.

35 "Manifesto del Futurismo (1909)", punto 9, en ZECCHINI, V. (a cura di): Futurismo e fascismo: manifesti e programmi, Bologna, 2000, pág. 20.

36 NICOLOSO, P.: op. cit., págs. 53 y 57.

37 “Manifesto del Futurismo (1909)", punto 11, en ZECCHINI, V. (a cura di): op. cit., pág. 21.

38 BIANCINI, B. (a cura di): Dizionario mussoliniano, Milani, Hoepli, 1939, cit. en CEDERNA, A.: Mussolini urbanista, Venezia, Corte del Fontego Editore, 2006 (1ª ed. Laterza, Roma, 1979), pág. 6.
} 


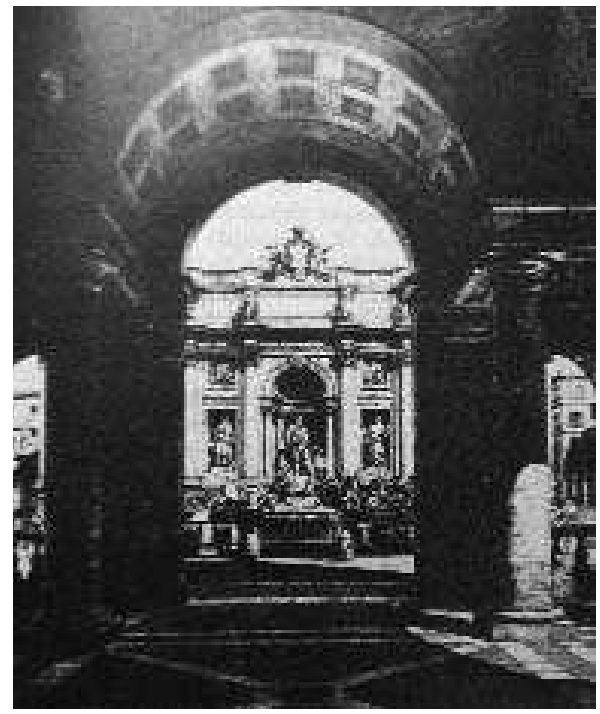

6. FosChINI-SPACCARELLI: Proyecto (no realizado) para la modificación del entorno de la Fontana di Trevi, enmarcando entre pilastras y columnas la via San Vincenzo. Reproducido en la Revista Capitolium, 1925.

deseo implícito y una provocación deliberada y unívoca, de origen doctrinal, que persigue un fin determinado: hacerse entender, estimular la respuesta del espectador y conectarlo con el objeto creado. Cuando la forma artística gusta o agrada, simultáneamente, se conforma un argumento que valida el elemento visualizado, se emite por lo tanto un juicio en que se incluye una valoración, y se cimenta además un criterio. Kant reconocía una tendencia natural en las personas para universalizar los criterios y el valor de éstos en sí mismos respecto de los objetos, a través de formas simbólicas ${ }^{39}$. Desde este punto de vista, la sensación de agrado atañe a la conciencia, transformándose en un sentimiento emotivo, que en una determinada situación, puede conducirnos a conectar nuestras experiencias personales con el valor que atribuimos a los objetos que las producen 40 . Finalmente, el valor que permanece asociado en el tiempo al objeto, lo termina convirtiendo en un elemento descriptivo del mismo41. Afianzar los valores del fascismo mediante el aspecto estético desempeña un rol decisivo en el discurso de Mussolini. Gobernar un pueblo para el Duce pasa por la necesidad de evocar imágenes lo suficientemente sugestivas como para impresionar y seducir a las masas, y el culto a la belleza y a la forma se configuran como fundamentos esenciales de la concepción fascista italiana para conquistar la fidelidad el pueblo ${ }^{42}$. Por esta razón, en la dramatización propia de la política fascis-

39 BARBERO ENCINAS, J. C.: La memoria de las imágenes. Notas para una Teoría de la Restauración, Ediciones Polifemo, Madrid, 2003, pág. 115.

40 Ibídem., págs. 215-217.

41 Ibídem., pág. 217.

42 BIANCINI, B. (a cura di): op. cit., pág. 178. 
7. ANTONIO MUÑOZ: Primo progetto per la sistemazione del colle Capitolino verso via Tor de'Specchi, 1930.

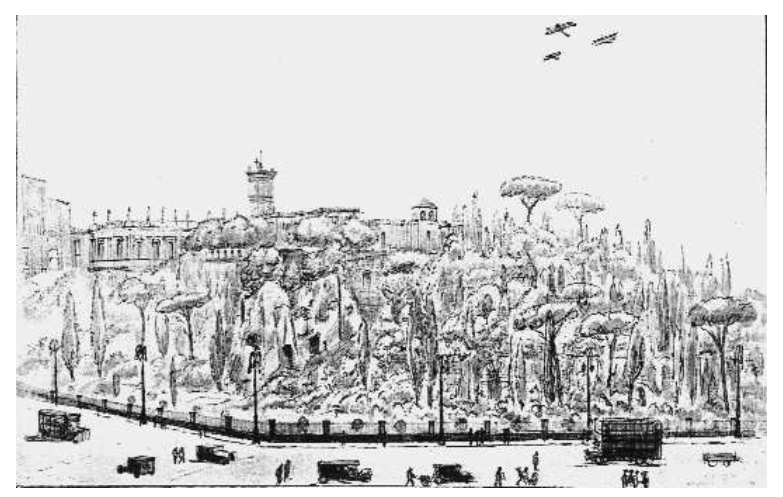

ta durante los años treinta, la ciudad de Roma se convierte en un inmenso archipiélago de escenarios teatrales, a los que se asiste para contemplar el alzamiento de nuevas arquitecturas que coexisten con estructuras preexistentes transfiguradas, pero en cualquier caso, ambientes fácilmente reconocibles como obra ejemplarizante del régimen, que al mismo tiempo, contribuyeron a edificar la imagen mítica del Duce.

Es posible que este ambiente de ebullición teórica direccionada favoreciese la reelaboración de la idea de Roma como gran capital, basada en modelos de otras capitales ochocentescas europeas como París o Berlín. No cabe la menor duda, de que la lectura social y política tradicional acerca de los fundamentos estratégico-militares de Napoleón III y el Barón Haussmann, respecto a las transformaciones urbanísticas de París hicieron mella en Mussolini43. En efecto, la ciudad eterna representaba la materia prima perfecta para poder continuar fantaseando con la idea de restaurar la imagen gloriosa de tan ansiado pasado (quimérico e incongruente) y crear una nueva Roma Imperial a golpe de piqueta: "Tra cinque anni Roma deve apparire meravigliosa a tutte le parti del mondo: vasta, ordinata, potente, come fu ai tempi del primo impero di Augusto"44. La Terza Roma está por deconstruirse. Y justamente utilizamos este término porque la aporía a la que responde esta visión utópica de la realidad, conduce a desnaturalizar la connotación positiva de la palabra construcción. Pues efectivamente se trata de demoler y deshacer; confeccionar insólitos y artificiosos escenarios bajo la lógica del durare, que transformarán irremisiblemente los trazados urbanos en un fárrago de atmósferas ficticias. La legitimación de tamaña demencia vino con la institución del Goveratorato en 1923 y la ejecución del Nuovo Piano Regolatore del 3145. Ambos proporcionaron carta blanca a las tentativas del

43 DATO, G. (a cura di): L'urbanistica di Haussmann: un modello impossibile?, Roma, Officina Edizioni, 1995, págs. 16-17.

44 SUSMEL, D.: op. cit., vol. XX, pág. 234.

45 El plan urbanístico de 1931 será aprobado por Decreto el 6 de julio de 1931 y dos años más tarde, se determinaría su asunción ante la Cámara y el Senado por Ley 24 de marzo de 1932, n 355. 


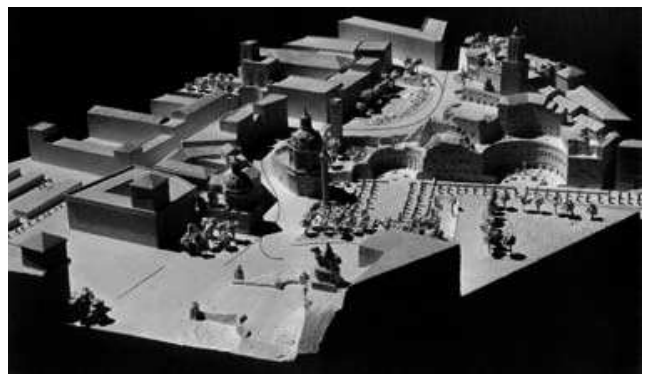

8. Maqueta para la reorganización urbanística de la zona de piazza Venezia y los foros, s.a. ASC, 1938.

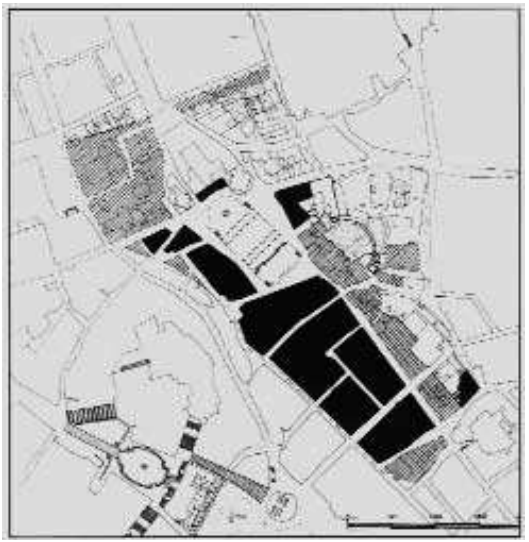

9. Trascripción del piano particularizado $n^{\circ} 5$ para la remodelación de la zona comprendida entre piazza Venezia, el Campidoglio y los foros. ASC, 02-05-1932.

Duce para reinventar la imagen de Roma, destruyendo y manipulando el tejido urbano a su antojo y sacralizar los símbolos del mito fascista ritualizando cada actuación. Por ejemplo, la colina capitolina y el Campidoglio constituyeron una de las zonas predilectas del Duce, por sus cualidades para desarrollar la dualidad escenográfica omnipresente en su discurso: revolución fascista y tradición clásica, y aspirar así a obtener la admiración del mundo hacia Roma ${ }^{46}$. Mussolini asume la decisión final de cada proyecto, desde su diseño hasta su ejecución y en cada aparición pública o en cada publicación, se revela su participación directa y constante, casi maníaca, en el vasto programa de actuaciones que preveía el Piano. A nivel teórico, las actuaciones contenidas en el documento consistieron fundamentalmente en el aislamiento de monumentos y la liberación de visuales y ambientes; en las zonas centrales se efectuarían los proyectos más importantes de sventramento (desmembramiento) de las masas arquitectónicas de inferior calidad arquitectónica y viejos núcleos más degradados -medievales y renacentistas en mayor medida- 47 . Demoliciones que en un primer momento debían estar limitadas a algunos puntos concretos con cotas de población densa y habitabilidad insalubre, pero que en la práctica, la improvisación y la multitud de planos particularizados constituyeron la única unidad de actuación efectiva del documento. Por dura que pueda parecer esta crítica, la evidente instrumentalización que supuso el plan urbanístico emprendido por Mussolini se concluyó como una inextricable maniobra política camuflada bajo criterios de risanamento

46 SUSMEL, D.: op. cit., vol. XXVI, pág. 187. Cit. en NICOLOSO, P.: op. cit., págs. 49 y 51.

47 PIACENTINI, M.: "Roma mussoliniana. II progetto del piano regolatore della capitale", en L 'ilustrazione italiana, 1/3/1931, n. 9, vol. IX, Anno LVIII, 1931. Págs. 312-313. 


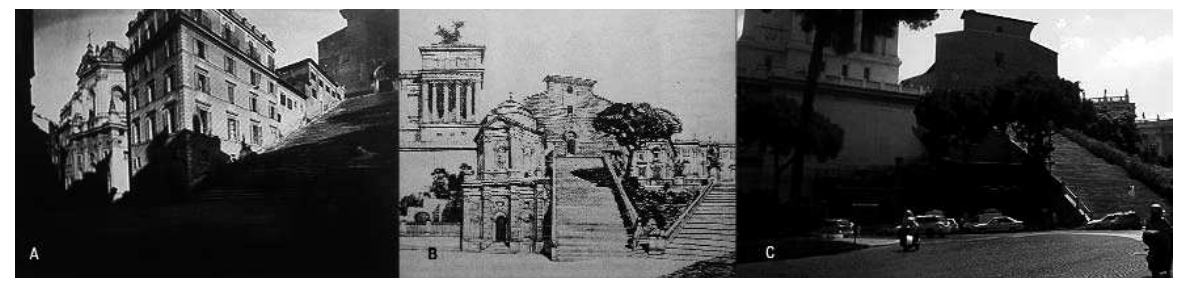

10. A) Via Giulio Romano y entrada a la piazza Aracoeli, e la iglesia de Santa Rita junto a un edificio barroco, 1887, s.n. Archivio Fotografico Comunale (AFC). B) GuSTAVO GIOVANNONI: Proyecto (no realizado) de reconstrucción y reubicación para la iglesia de Santa Rita, tras la remodelación de la plaza de Aracoeli. 1929. C)Piazza Aracoeli a los pies del Campidoglio en la actualidad. Con las sucesivas remodelaciones, la concepción de Miguel Ángel para esta plaza cerrada, estrecha y alargada se perdió para siempre. Foto: Autora. 2008.

(regeneración) higiénico y ambiental ${ }^{48}$. Las actuaciones urbanísticas orquestadas por el Duce no se ajustaron a ninguna disciplina de control urbanístico, y las fortísimas reestructuraciones que soportó el tejido histórico de la ciudad fueron en realidad, una auténtica excavación arqueológica de dimensiones descomunales que duró décadas. Las intervenciones originaron una trama urbana segmentada social y culturalmente, y desmenuzada en monumentos y edificios emblemáticos.

Entre 1926 y 1929 se llevó a cabo una irracional campaña de aniquilación de todo el barrio medieval a los pies del Campidoglio. Las múltiples excavaciones bajo la Piazza d'Aracoeli llevaron a la desaparición de la misma junto con las de Via della Bufola, Arco dei Saponari, Via della Pescheria y Vicolo della Campana; Santa Maria y San Andrea in Vincis; las casas medievales de Giulio Romano y Pietro della Cortona; el desmontaje y traslado de la iglesia de Santa Rita de Cascia (de Carlo Fontana) situada a los pies del Campidoglio, que fue recompuesta en 1940 en la via Montanara, en ángulo con la Piazza Campitelli; y la casa seicentesca de Miguel Ángel, que fue desmontada y reubicada en el Giannicolo, entre otros.

La unión de la Piazza Venezia con el Colosseo se efectuó mediante la técnica de la improvisación, y a medida que se realizaban las excavaciones arqueológicas se resolvían las decisiones. Los trabajos para la apertura de la via del Impero o dei Fori Imperiali (1932) comenzaron sin analizar siquiera la viabilidad de las obras o

48 No nos detendremos en profundizar en estos aspectos, pues al respecto se pueden consultar los trabajos: CALDERÓN ROCA, B.: "La gestión de la ciudad histórica en la Roma fascista 1: la instrucción sobre restauro urbano a través de la obra de Gustavo Giovannoni" y "La gestión de la ciudad histórica en la Roma Fascista 2: Urbanística, Piani Regolatori y conservación del Patrimonio a través de la trayectoria de Marcello Piacentini", ambos en Boletín de Arte $\mathrm{n}^{\circ} 28$, Departamento de Historia del Arte, Universidad de Málaga, 2007, págs. 253-306. 


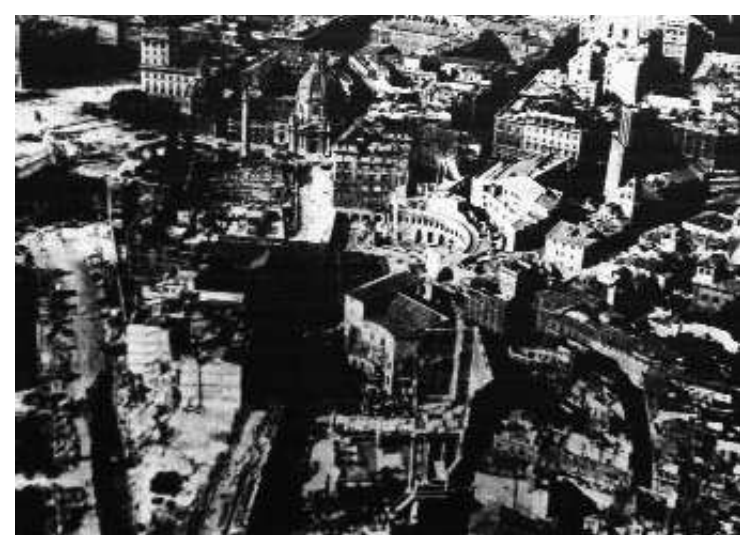

11. Demolición de los foros. $A F C, 1932$ ca.

la trayectoria de la misma. No obstante, la tentativa de la nueva arteria continuó su delineación, partiendo de un proyecto rectilíneo imposibilitado en sí mismo por las barreras geológicas de la colina, forzándose su trazado en base a condenar el entramado urbanístico medieval y gran parte de las fábricas de época romana y barroca que cubrían los foros ${ }^{49}$ y configuraban las zonas comprendidas entre el Campidoglio, Foro Romano, el Palatino Trajano, Teatro di Marcello, Circo Máximo y Piazza Venecia. En el trascurso de las excavaciones en el Foro de Augusto (1924-26) se produjo el descubrimiento de los Mercados Trajanos y hubo que proporcionar una panorámica acorde con el efecto estético y escenográfico ansiado, mediante el aislamiento de los foros. Así pues en 1929, se demolieron la iglesia medieval de San Basilio, la de San Nicola ai Cesarini y el Palazzo Acquati. La zona más antigua, ubicada a ambos lados del Corso Vittorio Emanuele (desde Via Arenula, Campo dei Fiori, Via Giulia, Via Monserrato, Via Coronari, Via Governo Vecchio y Piazza Navona hasta Corso Rinascimento) se encontraba en avanzado estado de deterioro y se procedió al desmantelamiento y demolición de las áreas afectadas. La apertura de la Via delle Botteghe Oscure completó el sistema viario desde Piazza Venezia hasta Largo Argentina 50 . La construcción de gran arteria del Mare (actual Via del Teatro Marcello) entre 1930 y 32, surgió de las demoliciones comprendidas entre la Piazza Venezia y

49 Señalamos algunas de las pérdidas: Ios jardines del Cinquecento del Palacio Rivaldi; la iglesia de San Adriano (la Curia); de los santos Cosme y Damiano; la base del Colosso de Nerón y de la Meta Sudante (único vestigio de fuente monumental antigua conservada hasta la fecha); algunos pozos del siglo XVIII; importantes restos arqueológicos del período republicano; un magnífico fragmento de opus incertum y opus reticulatum de época imperial e incluso un templete de gran importancia para el estudio de la topografía de la Roma antigua: Compitum Acili. En 1933 Via del Impero adquiere su aspecto definitivo tras la demolición del último bloque de casas emplazadas entre el foro de César y el de Augusto, así como de la iglesia de San Urbano y San Pantano. COLINI, A. M.: "Scoperte tra il Foro della Pace e I'Anfiteatro", en Bullettino della Commissione Architettonica Comunale, 1933, págs. 79 y ss.

50 PIACENTINI, M.: "Problema difficili dell'urbanistica romana. Per un decoroso sopravivere della vecchia Roma", en Strenna dei romanisti, XIV, Roma, Staderni Editore, 1953. Págs. 26-27. 


\section{artículos Roma, archipiélago de la memoria. La ciudad del Duce...}

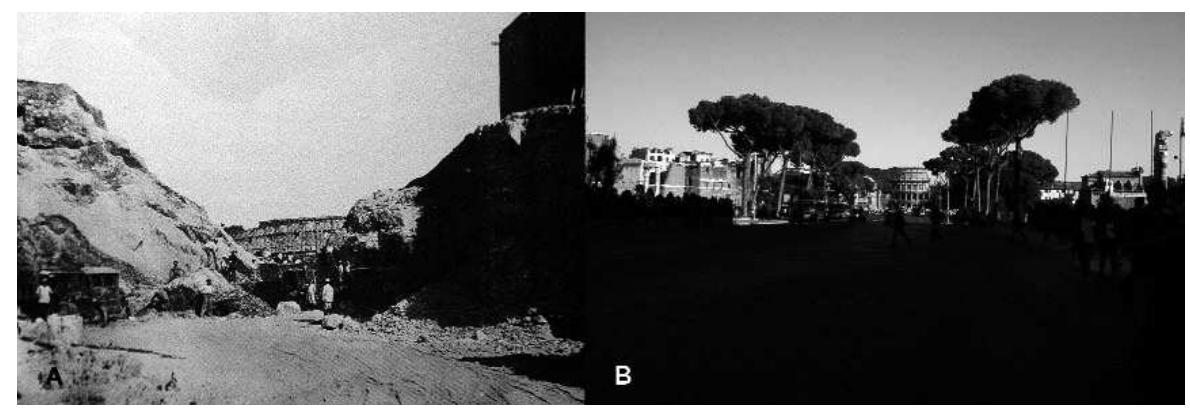

12. A) Apertura de la antigua via dell'Impero desde piazza Venezia, con el Colosseo al fondo. AFC, 1932 ca. B) La gran "passeggiata archeologica": via dei Fori Imperiali en la actualidad. Foto: Autora. 2008.

la Bocca de la Verità, y produjo el aislamiento del Teatro Marcello (1926-1933) y la desaparición de diversas estructuras medievales que cerraban las arcadas del mismo; el aislamiento de los templos de Vesta y la Fortuna Viril, el Arco di Giano, la iglesia de San Nicola in Carcere y la Casa dei Cresenci51.

\section{LA REALIDAD: ROMA, ARCHIPIÉLAgo de LA MEMORIA.}

La estrategia político-cultural emprendida por Mussolini estuvo dirigida a consolidar la doctrina fascista, configurándose como la primera tentativa seria de organización de fuerzas culturales agrupadas en torno a una ideología, que darán origen en 1925 al Manifesto degli Intellettuali del fascismo52. A partir de aquí el fascismo se insertaba en clave patriótica y nacionalista dentro de la tradición italiana, resumiendo lo más representativo de la propia historia del pueblo. El Duce supo aprovechar la debilidad política de sus adversarios para arraigarse profundamente en el tejido político y cívico italiano, esbozando los postulados ideológicos que definirían la futura política cultural del régimen mussoliniano ${ }^{53}$. El Duce irá trasformando velozmente la sociedad italiana en "la sociedad del espectáculo", y parafraseando a Luigi Pirandello: "todo aquello que es público se convierte inevitablemente en espectáculo", basta recordar los discursos de Mussolini en el Palacio Venecia, o cuando recorría a cabaIlo la recién inaugurada via del Impero a modo de condottiero romano; ambas anécdotas constituyen memorables episodios de la historia italiana del espectáculo. El hilo conductor del discurso giraba en torno a colonizar la historia mediante la arquitectu-

51 Vid. CEDERNA, A.: op. cit., págs. 129-196.

52 "Manifesto degli Intellettuali del fascismo", en ZECCHINI, V. (a cura di): op. cit., págs. 69-75.

53 PEÑA SÁNCHEZ, V.: op. cit., págs. 118-119. 
ra, convirtiéndose ésta en el instrumentum regni, la herramienta por antonomasia del gobierno para obtener el consenso de las masas, además de una fórmula magistral para mostrar y consolidar el propio poder, pues se consideraba un herramienta con gran capacidad de sugestión y eficaz como medio de comunicación.

Retomemos de nuevo el hilo de nuestro discurso principal, Roma concebida como un archipiélago de islas, de imágenes que evocan un pasado histórico dispar y fragmentado. El régimen de Mussolini manipuló la memoria histórica del pueblo italiano dejando vestigios arquitectónicos con mensajes erróneos e indelebles, pero afortunadamente, su convicción sobre la necesaria continuidad de los monumentos, para que éstos pudiesen arrojar significados y difundir eternamente el mito de la potencia y superioridad de la Italia fascista, quedó desmontada en la última etapa de la Segunda Guerra Mundial. Las arquitecturas edificadas durante el régimen fueron abatidas como símbolos falsos y retóricos de una dictadura que adulteró durante dos décadas la cultura artística de un país, transfigurando sus estructuras arquitectónicas y desdibujando el semblante de las ciudades. Las transformaciones urbanísticas resultaron más evidentes en Roma que el resto de Italia, y Mussolini no cesó en el empeño de alimentar con firmeza y absurda convicción, la idea de competir con la antigüedad clásica y tratar de aproximar el pasado de Roma a la población, mediante un proceso de construcción de imágenes disgregadas, resemantizadas y anacronizadas. De ahí que el centro histórico de Roma sea en realidad, un archipiélago de la memoria. Socialmente, la imagen de la memoria de la ciudad-descontextualizada y falseada-, se utilizó para mantener una apariencia de continuidad histórica con el pasado que en realidad no existía, pero que resultaba necesaria para moldear la identidad cultural de la sociedad. En consecuencia, cualquier forma de pensamiento contrario a esa "idea de continuidad histórica" debía ser erradicada. De ahí que durante el ventennio el pasado se reinvente continuamente y la historia se transforme en metahistoria, sin duda para reforzar una pseudomemoria construida sobre pilares mitológicos, satisfaciendo así la triple necesidad que abordábamos en los primeros párrafos de este trabajo:

1. Necesidad de ser comprendido. Mussolini hacía constante referencia a la necesidad del hombre de dotarse de símbolos que sirvan para reforzar su identidad. En estos términos, se sirvió de la arquitectura para realizar su proyecto antropológico de rehacer la historia italiana y construir al uomo nouvo.

2. Necesidad de detener el tiempo. El Duce concebía un proyecto ideológico más eficaz, cuanto mayor fuese su capacidad para trasmitir un mensaje y la posibilidad de eternizarlo. Los monumentos, por su función pedagógica, constituyen símbolos de la hegemonía política y por ello debían poseer la condición de durabilidad: "la arquitectura con su constante presencia modifica el carácter de las generaciones ${ }^{54}$. 
3. Necesidad de afianzar los valores. El Duce se consideraba a sí mismo una figura carismática de naturaleza guerrera, que fue elegida para guiar los destinos de la nación italiana y consolidar su civilización, capaz de dominar al mundo como en época imperial. Convencer a la población de su misión revolucionaria y arraigar el fascismo en la tradición italiana constituyó el principal valor de su doctrina. Para ello hubo de aglutinar al pueblo en torno a la figura de un nuevo César, icono que personificó él mismo, modelo de hombre nuevo, guerrero y constructor al mismo tiempo ${ }^{55}$.

\section{Epílogo.}

Walter Benjamin afirmaba que la ciudad histórica es experimentada principalmente, dentro de la dimensión del recuerdo. Para el nativo, la esencia urbana se halla en las modificaciones que el texto-ciudad le ofrece, mientras que para el forastero, dicha esencia reside en la inmediatez del instante captado. De ahí la importancia para la memoria que reclama Alberto Maria Racheli, pues afirma que ésta constituye la superposición de recuerdos e imágenes colectivas que no deben jamás extirparse de la compleja sucesión temporal y espacial que constituye la realidad urbana ${ }^{56}$. Las imágenes fragmentadas que exhibe la urbe romana en la actualidad son adquiridas por nuestra mente a través del recuerdo, conformando una secuencia de formas en las que a menudo, no existe diálogo semántico continuado. Las formas de la ciudad histórica no pueden transmitir su mensaje completo, debido a que no se ha preservado la combinación sintáctica entre las formas y su contexto narrativo.

Como bien afirma Racheli, durante años se han ocasionado daños irreparables a un vasto territorio de la historia, sin actitudes, ni aptitudes para valorar la pluristratificación que los mensajes arquitectónicos de la ciudad ofrecía. La presencia de la infraestructura que constituye el contexto determina el sentido final del mensaje, y por lo tanto, la carga semántica de las formas y la asociación de contenidos, así como las intrahistorias particulares vinculadas a la historia de la ciudad, se desvanecen con la eliminación del contexto que las articula y les confiere pertinencia formal. Comunicar significa etimológicamente poner en común, y una situación no puede ser plenamente aprehendida y compartida si no consideramos las interrelaciones que la caracterizan 57 .

\footnotetext{
54 Voz de la palabra Architettura recogida en "Dizionario del fascismo", en Dizionario di politica, Istituto dell'Enciclopedia Italiana, Roma, 1940, vol. I, pág. 159.

55 NICOLOSO, P.: op. cit., págs. XVI; 58 y 61.

56 RACHELI, A. M.: Antico e moderno nei centri storici. Restauro urbano e architettura, Roma, Gangemi, 2003, pág. 57.

57 CALDERÓN ROCA, B.: "Más allá del patrimonio arquitectónico: La ciudad histórica como imagen simbólica de una identidad cultural en construcción”, en Isla de Arriarán, n XXIX, junio 2007, pág. 96.
} 
Nos encontramos en un momento histórico en el que debemos de nuevo rehacer la historia, sin encubrir o adulterar episodio, hecho o acontecimiento alguno. La continuidad de la memoria colectiva depende de la capacidad de los individuos para rememorar cualquier fragmento del pasado que sirva para hacer legible la ciudad, y ésta debe reactivarse "(...) nutriéndose progresivamente de recuerdos que la propia comunidad va incorporando y verificando paulatinamente a su propia memoria"58. Afortunadamente, tras décadas de infausto silencio, la ciudad histórica de Roma aprende a relatar su significado más íntimo.

58 Ibídem., pág. 82. 